\title{
Possibilities of CSF Pressure Diagnosis -A Review-
}

János VAJDA and Emil PÁSZTOR

National Institute of Neurosurgery, Budapest, Hungary

\section{What must be understood about CSF pressure}

Our task is to present a review of the current understanding concerning the diagnostic possibilities of CSF pressure (CSFP). Therefore, CSFP measurement and the different methods used should be our focal point. One of the clues for interpretation of intracranial pressure (ICP) is a clear-cut description of which method was chosen for recording or analysis.

The intracranial cavity has to be regarded as a complex entity which contains at least three compartments. The knowledge of relationships among these compartments is indispensable when we are talking about CSFP diagnosis. In the day-to-day practice ICP recording should be understood in terms of CSFP monitoring, i.e., measurement of any compartment at any site is possible and could be informative in the estimation of ICP pathology.

If we stayed close to the term CSFP monitoring, we could talk only about direct spinal or ventricular fluid pressure measurement. These used to be applied most frequently in clinics. They have gradually lost importance due to some disadvantages and less invasive methods have been developed to evaluate CSFP. At present determination of the exact level of ICP (we think this term is the most appropriate) is not sufficient but estimation of intracranial elastance or compliance provide data which are supposed to be the most informative.

\section{Physiological aspects}

In normal adults, the ICP is regulated by various processes and maintained between 0-2 kPa, i.e. $200 \mathrm{~mm} \mathrm{H}_{2} \mathrm{O}$.

From the viewpoint of static volumes, the intracranial space is a closed system, i.e. each compartment including the cerebral blood volume (CBV), brain mass and CSF can increase in volume to the detriment of the others. The volume of any compartment increases up to a certain point without significant decrease in the others but ICP elevation occurs as a response. Under normal circumstances during a strong cough, an increase of venous $\mathrm{CBV}$ is followed by raised ICP.

From the viewpoint of dynamic volume changes, the craniospinal space is an open system, i.e. the two compartments show a slower or faster waxing and waning. The arterial input increases suddenly in each cardiac cycle, and so does the CBV which is decreased continuously at a slow rate by the venous outflow. This speed difference causes rapid ICP elevation in each cardiac output which is called CSF pulse pressure.

There is no knowledge about such dynamic differences between the formation of CSF at the choroidal plexuses and absorption at various venous channels but these processes also behave according to the properties of an open system and the CSF input and output are all measurable values. ${ }^{18,20)}$

Thus, a slow increase in volume in the craniospinal space evokes a buffer phenomenon and the ICP remains normal depending on the capacity of these compensatory mechanisms. If the increase of volume is too fast, the compensation is exhausted in a short time and the ICP rises.

Plotting the values of volume against those of evoked pressure results in an exponential curve, i.e. volume/pressure curve. By inflating an intracranial balloon at a constant rate of infusion over a period of many hours, a situation arises that simulates the most common volume/pressure relationship encountered in neurosurgery, and the nearly horizontal portion of the curve is mainly a function of the compliance of the intracranial space. Two principal events occur in this period. CSF expressed from the cranial cavity and the brain is distorted 
and molded to the expanding mass. The rate at which the molding takes place and the consequent substantial alteration in the brain are a function of the elastance of the craniospinal space. It is probably true that even with the slowest infusion there is a pressure gradient across the underlying brain and the height of this gradient is a function of the rate of the space occupying process.

\section{Clinical situations of interest regarding CSFP measurement}

Let us consider the different pathological conditions in each compartment.

1. CSF : Benign intracranial hypertension - Reye-Johnson syndrome

Spinal tumors

Formation disorders-papilloma of the choroid plexus

Absorption disorders-

a) congenital hydrocephalus

b) normal pressure hydrocephalus

Passage disorders-

a) developmental problems

b) axial tumors

2. CBV: Intracranial sinuses-

thrombosis

occlusion

stenosis due to tumors or infection

3. Masses: Tumors

Hypertonic attack

Hemorrhages
Abscesses
Cysts
Brain swelling-
$\quad$ injury
infection
metabolic disorders

\section{Historical background}

It has been possible for $80-100$ years to measure hydrostatically CSFP by the route of lumbar and ventricular puncture ever since the time of Quincke, Dandy and others. Normal and pathological values have been described.

The works of Eli Goldensohn, ${ }^{7)}$ Pierre Janny $^{8)}$ and Henry Ryder ${ }^{21)}$ signified a new period of understanding of CSFP between 1950 and 1955. They independently first used modern electronic transducers for continuous
ICP measurement. They elucidated the influence of $\mathrm{CO}_{2}$ inhalation and vasodilation on ICP and also observed pulse amplitude which could be demonstrated only using the isovolumetric method, as well as the plateau-like form of periodic intracranial hypertension. Continuous ventricular fluid pressure (VFP) monitoring in neurosurgical practice was first proposed by them.

Lundberg's monograph ${ }^{13)}$ after comprehensive clinical and experimental research in 1960 summarized the complete status of the topic. Growing interest in ICP created by Swedish and German scholars resulted in series of biannual ICP meetings, a magnificent forum of international research. In the early seventies a new mathematical aspect was successfully developed. Marmarou and Shulman ${ }^{14,22)}$ and many later teams $2,3,4,9,22,23$ ) have reported well-known and new experimental and clinical findings applying mathematical equations and models. Now analysis of ICP and related data is not imaginable without computer-systems.

Other research groups are dealing with CSF hydrodynamics, and with absorption and formation in the light of pressure relations. ${ }^{4,6,22,23)}$ Others study the complexity of intracranial space and the cerebrovascular factors. ${ }^{2,9,12,14,16,18,21)}$ Beside these rather basic approaches, there are a lot of papers about ICP problematics in clinical conditions, describing how different factors of ICP behave under various circumstances such as subarachnoid hemorrhages, the postoperative period and head injuries, etc. ${ }^{4,11,13,15,19,25,26)}$

V. Methods for direct measurement of ICP ICP measurement can be performed at different sites intermittently or continuously, and it may take minutes to days. If intracranial hypertension is self-evident from the curve obtained, a shorter time of monitoring might be sufficient but in the vast majority of cases, a few minutes do not give information about frequent waxing and waning in ICP (Figs. 1, 2) that occur under abnormal circumstances. Continuous monitoring provides warning signs of brain herniation, early detection of serious situations developing, and the efficacy of treatment, and thus gives information about the final outcome or indication of surgical intervention. 


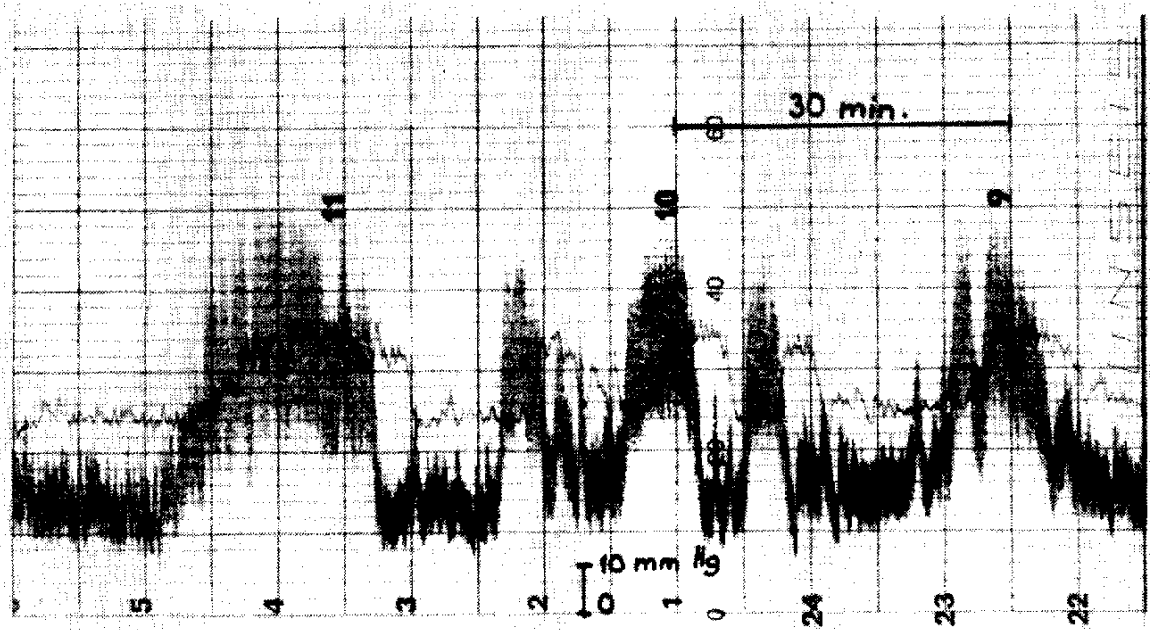

Fig. 1 Long term registration of direct and integrated epidural pressure in a case of cystic glioma in the thalamus with occlusive hydrocephalus preoperatively. Some pressure waves of $75 / 40 \mathrm{mmHg}$ lasting 5-15 minutes occur arrhythmically. The well-known plateau waves do not show a uniform appearance. The height of elevations is, however, constant.

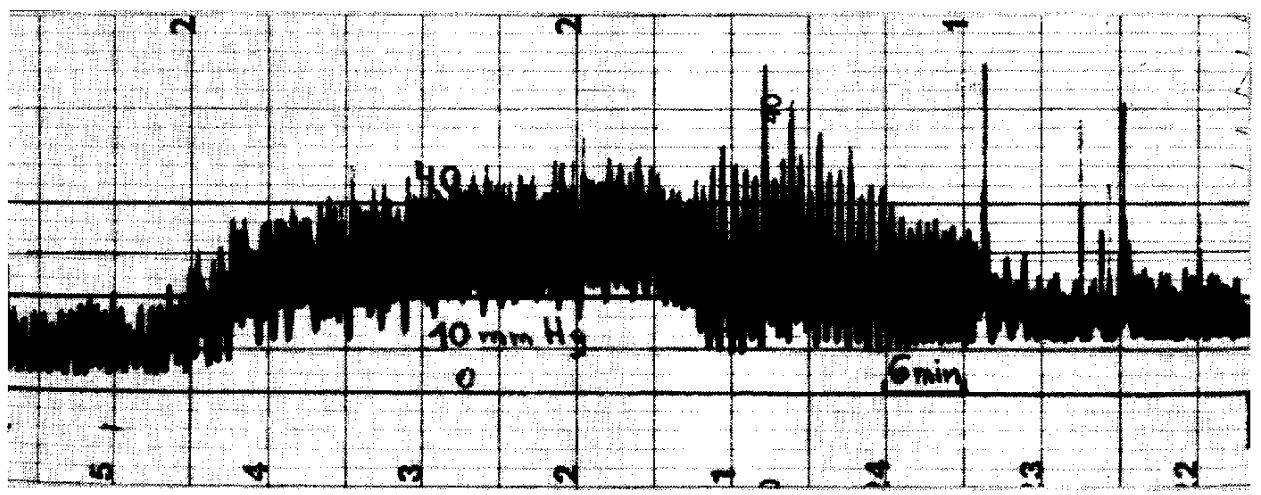

Fig. 2 Detail from an overnight registration of EDP in a case of normal pressure hydrocephalus two years after a head injury. During paradox sleep, rhythmic oscillation of $15-50 \mathrm{mmHg}$ can be seen at a frequency of $2 / \mathrm{min}$. This positive reaction to volume load can be regarded as indicating that shunt inplantation is effective.

Each method of monitoring has advantages and limitations, and the method used should therefore be applied according to the individual situation (Table 1).

Spinal fluid pressure (SFP) can be measured only in cases of communicating craniospinal CSF spaces due to the danger of tonsillar herniation. It is performed via a lumbar puncture or drainage of the subarachnoid space. Its advantage is the simplicity of entering the $\mathrm{CSF}$ without further invasive opening the skull space. Normal pressure and congenital hydrocephalus can be investigated easily in this way. ${ }^{6)}$

Brain tissue pressure recording requires the so-called wick catheter which is placed in the brain substance via a burr hole in experiments or macroscopically during open surgery. The small catheter filled with mock CSF has a brush at its top and the capillary properties allow liquid contact between the tissue and transducer. This method is used in hemispherial surgery cases.

VFP determinations are most frequently used in clinical practice due to the technical easiness. Indwelling catheters can also be used 
Table 1

ICP monitoring

\begin{tabular}{|c|c|c|}
\hline Direct & & Indirect \\
\hline $\begin{array}{l}\text { Spinal fluid pressure } \\
\text { Brain tissue pressure } \\
\text { Ventricular fluid pressure } \\
\text { Epidural pressure } \\
\text { Subdural pressure } \\
\text { Transcutaneus pressure }\end{array}$ & & $\begin{array}{l}\text { Echo-EG pulsation } \\
\text { Diaphanography (rCBV) }\end{array}$ \\
\hline \multicolumn{3}{|c|}{ Estimation of ICP dynamics } \\
\hline $\begin{array}{l}\text { Volume load to } \\
\text { CSF compartment }\end{array}$ & Brain mass & Cerebral blood volume \\
\hline $\begin{array}{l}\text { Spinal or ventricular } \\
\text {-infusion } \\
\text { - bolus } \\
\text { - withdrawal }\end{array}$ & $\begin{array}{l}\text { epidural or } \\
\text { subdural balloon } \\
\text { inflation }\end{array}$ & $\begin{array}{l}\text { cardiac cycle } \\
\text { jugular compression } \\
\mathrm{CO}_{2} \text { inhalation }\end{array}$ \\
\hline
\end{tabular}

Isotope clearance

for X-ray investigations and for withdrawing of CSF volume at the same time if it seems necessary. Its main disadvantage is that it requires larger ventricles than normal. ${ }^{19)}$

Epidural pressure recording seems to be rather useful. It does not require immediate contact with CSF spaces which might result in infections. Another advantage is that it can be used in cases of head injury or supratentorial space-occupying lesions with compressed ventricles. Because of technical advances, miniaturized and telemetrized systems have appeared using membrane connection through a burr hole directly over the dura or separated by an artificially created small fluid reservoir, and an oscillator method. The cylinder-shaped sensor contains a passive electrical circuit consisting of a wire coil and a capacitance. The dural movements caused by pressure change the internal capacitance which alters the resonant frequency in the sensor. An external sensing coil that radiates a modulated signal is placed on the skin over the implanted sensor. Its clinical use requires some corrections but it can be considered sufficiently precise to show 1-2 $\mathrm{mm} \mathrm{H}_{2} \mathrm{O} /$ day of drift rate only, and has proved to be capable of working for several months (Figs. 1, 2 and 3).

Direct external ICP monitoring is only possible in infants over their open fontanelles or in cases of skull defects due to various reasons with contact sensors. This is known as the transcutaneous method and shows some possibilities, but it has strong limitations.

Subdural pressure monitoring is discussed at the end because it is less important. In cases of chronic subdural hematomas or infantile subdural effusions, information about the clinical course can be gained by introducing subdural catheters and surplus fluid can occasionally be removed via the same route. ${ }^{19}$ )

\section{Methods of testing and estimation of ICP elastance and compliance}

Although ICP monitoring has become a part of routine neurosurgical investigations, it is evident that the exact level of ICP by long term monitoring can not show the pathology in every case and particularly does not tell us the severity of the ICP status.

Data have been collected from many centers about different clinical situations where higher intracranial elastance required surgical intervention but the ICP itself was in the normal range. Therefore the intracranial space has to be tested to determine its volume-buffering capacity. Reliability of these methods exceeds that of continuous monitoring $4,11,17,25$ ) (Table 1).

From the reports of Katzman and Hussey, $1970^{10)}$ many modifications and special applications of infusion volume load to CSF 


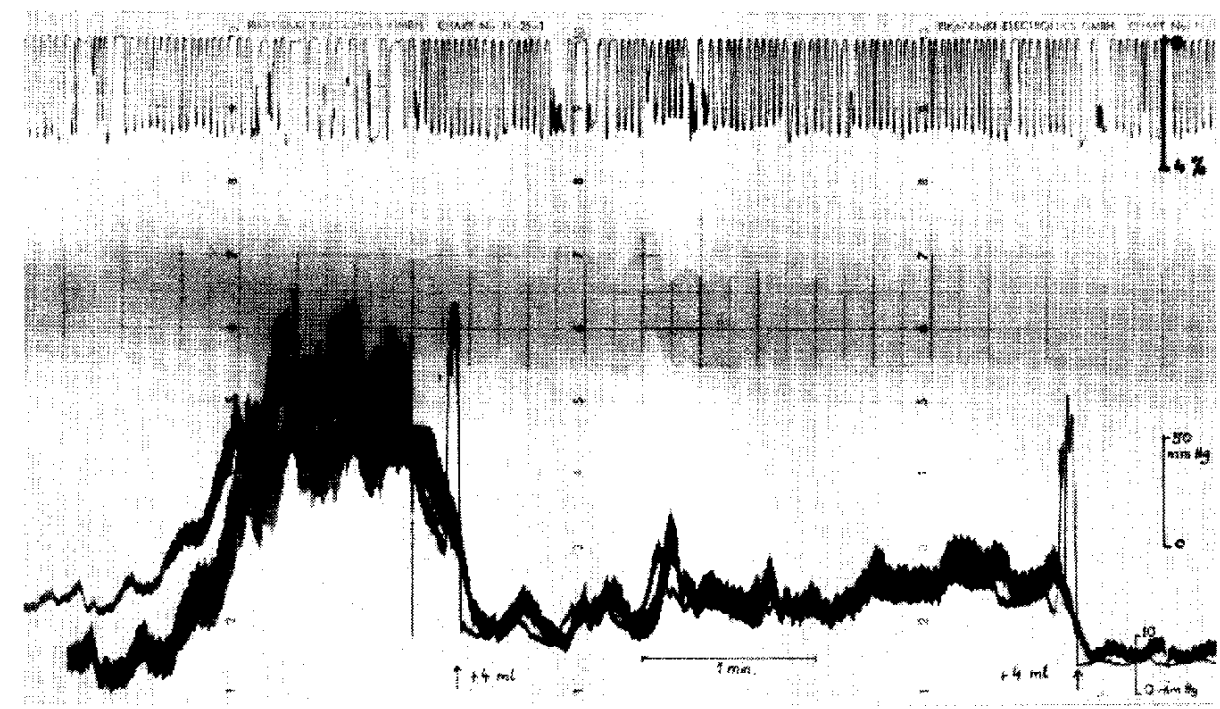

Fig. 3 Spinal fluid volume load testing in the same patient. The upper row demonstrates the $\mathrm{CO}_{2}$ content of expired air. The middle row shows the arterial pressure, and the lower rows show EDP and SFP registered simultaneously. In the resting state $(5 \mathrm{mmHg}$ ), a volume load of $4 \mathrm{cc}$ with bolus injection into the spinal cavity causes a pressure elevation of $26 \mathrm{mmHg}$ (ca. $3.4 \mathrm{kPa}$ ) in both epidural and spinal fluid spaces. When the same amount of fluid was added at a higher ICP $(12 \mathrm{mmHg}$ ), it evoked a B wave of $60 \mathrm{mmHg}$. Further elevation of ICP after bolus injection can be explained by the more sensitive pressure reaction of the craniospinal space to the transient CBV-loading delivered by each cardiac cycle. It is noticed that intracranial environment gradually shifts to the right on the volume/pressure curve.

When the spinal volume-load test was repeated with a smaller amount of mock CSF, a smaller pressure $(25 \mathrm{mmHg}$ ) reaction provoked a decrease with typical oscillations.

compartments were developed and proposed for different pathologies. In these tests, mock CSF was infused into the spinal CSF space $^{6)}$ or the ventricle at a constant volumetric rate or at constant perfusion pressure until the craniospinal system achieved a new steady state pressure and volume or until it was clear that new steady state conditions could not be attained. In studies of this type the infusion rate of CSF volume is rather slow and they are employed mainly for the determination of CSF absorption, a parameter of CSF outflow resistance. ${ }^{15}$ )

In the second category of CSF volume/ pressure tests, a bolus alteration (approximately an instantaneous change) in CSF volume is produced and measurements are made, both of the immediate change in $\mathrm{ICP}^{23)}$ and of the rate of its decay ${ }^{17,25)}$ toward resting ICP. It is used mainly to assess the elastic properties of craniospinal spaces and can predict the risk of elevation of ICP (Figs. 3 and 7).

The bolus technique has a special form in which a small amount of CSF is withdrawn and the consequent decrease in ICP is plotted against the decrease of CSF volume.

Under experimental conditions, the most frequently applied method for estimation of ICP dynamics is balloon inflation at various sites. It simulates the volume load on the mass compartment and has proved to be a good model for intracranial space-occupying lesions and their effects. ${ }^{2,12)}$

As it has been clearly demonstrated for many years, CBV has an immediate and significant effect on the intracranial elastance. ${ }^{11,25)}$ On the higher part of the volume/pressure curve, the same transient CBV change produced by the cardiac cycle causes a larger ICP pulsation and therefore efforts were made to estimate ICP dynamics from the data of the effect of CBV changes on ICP. ${ }^{27)}$ When pulse ampli- 


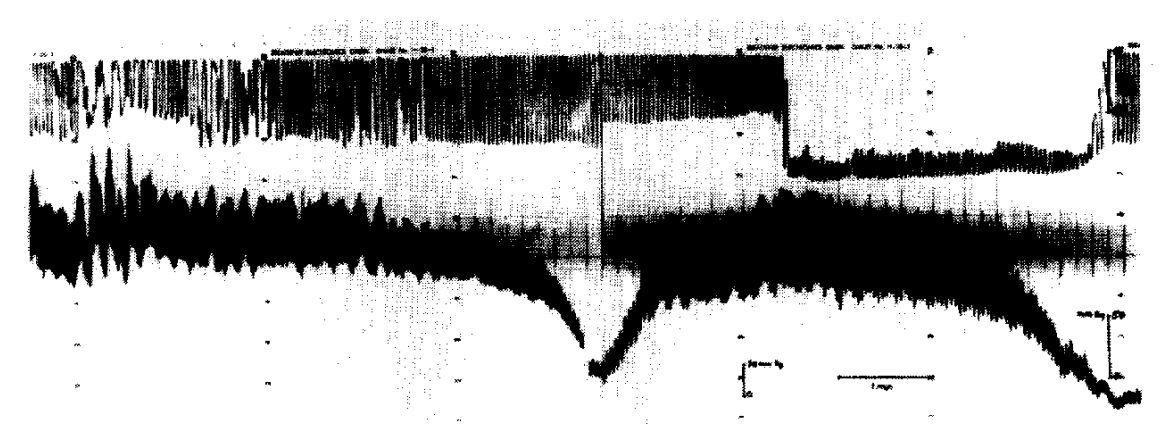

A

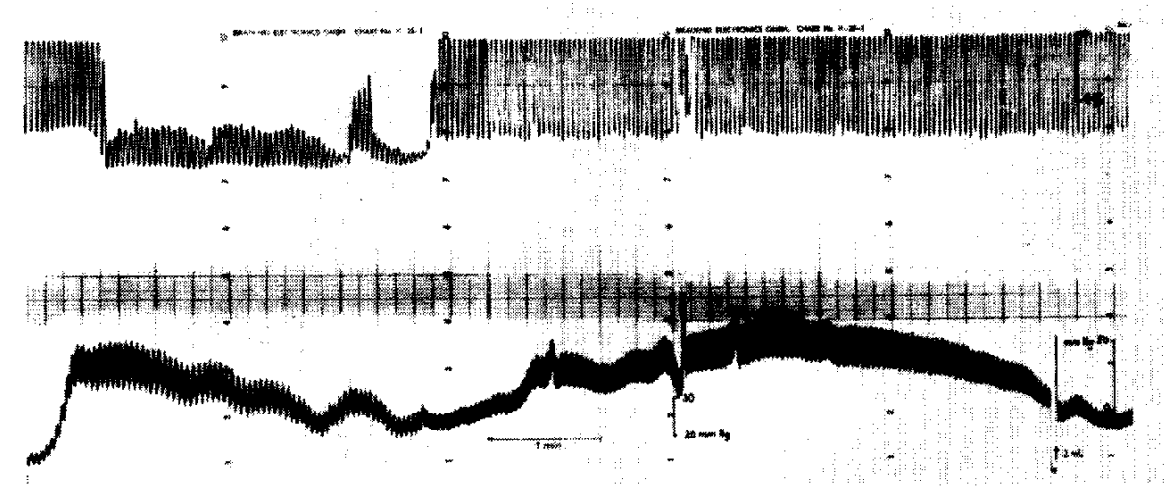

B

Fig. $4 \mathrm{~A}$ : Volume load test by bolus injection into the right ventricle and CBV load in a patient with a cerebellar astrocytoma preoperatively at different arterial pressure levels. The upper two rows are as in the previous figure. The lower row demonstrates direct monitoring of VFP. At resting arterial pressure (140/80 $\mathrm{mmHg}$ ) the $\mathrm{CBV}$ increase was caused by the vasodilation effect of $\mathrm{CO}_{2}$ and the later CSF volume load of $2 \mathrm{cc}$ provoked waves as high as $75 / 50$ and $85 / 60 \mathrm{mmHg}$ respectively.

$\mathrm{B}$ : When these tests were repeated at a lower blood pressure of $100 / 65 \mathrm{mmHg}$ after i.v. administration of $50 \mathrm{mg}$ of Arfonad, the pressure responses obtained were significantly smaller as were the amplitudes of CSF pulse pressure due to transient CBV changes.

tudes at various levels of ICP are analysed during oscillation due to sleep or during other modulations such as respiratory effect changes in the CSF, the pulse pressure to ICP ratio truly reflects changes in the slope of the volume/ pressure curve (Figs. 3, 4B, 5 and 6).

Alteration of arterial blood pressure with drugs and alteration of $\mathrm{CBV}$ by $\mathrm{CO}_{2}$ inhalation make it possible to determine the cerebrovascular influence on the craniospinal space and therefore the exact level of elastance can be predicted (Fig. 4B).

In a similar way compression of the jugular veins increases the ICP due to the increase of CBV. During the test ${ }^{5)}$ a curve is obtained with two different slopes, and the difference between them is related to the elastance. A more precise investigation of the type is when the patient breathes into an anesthetic mask in which the pressure has been systemically raised: positive end-expiration pressure (PEEP). ${ }^{1)}$ First, the PEEP is raised to $50 \mathrm{~mm}$ $\mathrm{H}_{2} \mathrm{O}$ and held at that level for 3-4 respiratory cycles. The test is repeated with additional $50 \mathrm{mmH}_{2} \mathrm{O}$ increments at intervals of several minutes between tests. The slope of the curve of ICP versus PEEP is taken as a measure of craniospinal compliance.

VII. Sophisticated indirect methods for estimation of ICP

The above-mentioned tests are more or less 

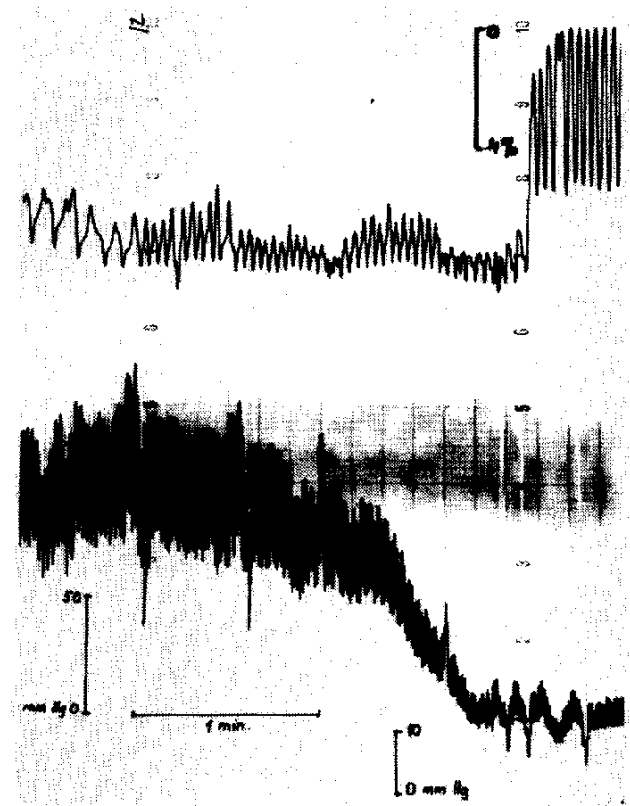

Fig. 5 CBV load test in a case with communicating hydrocephalus complicated with extrasystolia. The upper two rows are as in the previous figures. The lower row demonstrates VFP under a volume load. When the patient was asked to breath air containing $8 \%$ instead of $0.03 \% \mathrm{CO}_{2}$, the cerebral vessels were delated and the CBV increased resulting in the volume load to the craniospinal cavity. At each cardiac extrasystole blood pressure there was a sudden equal decrease which corresponds to the sudden decrease in VFP. These decreases were much more pronounced at high levels of ICP.
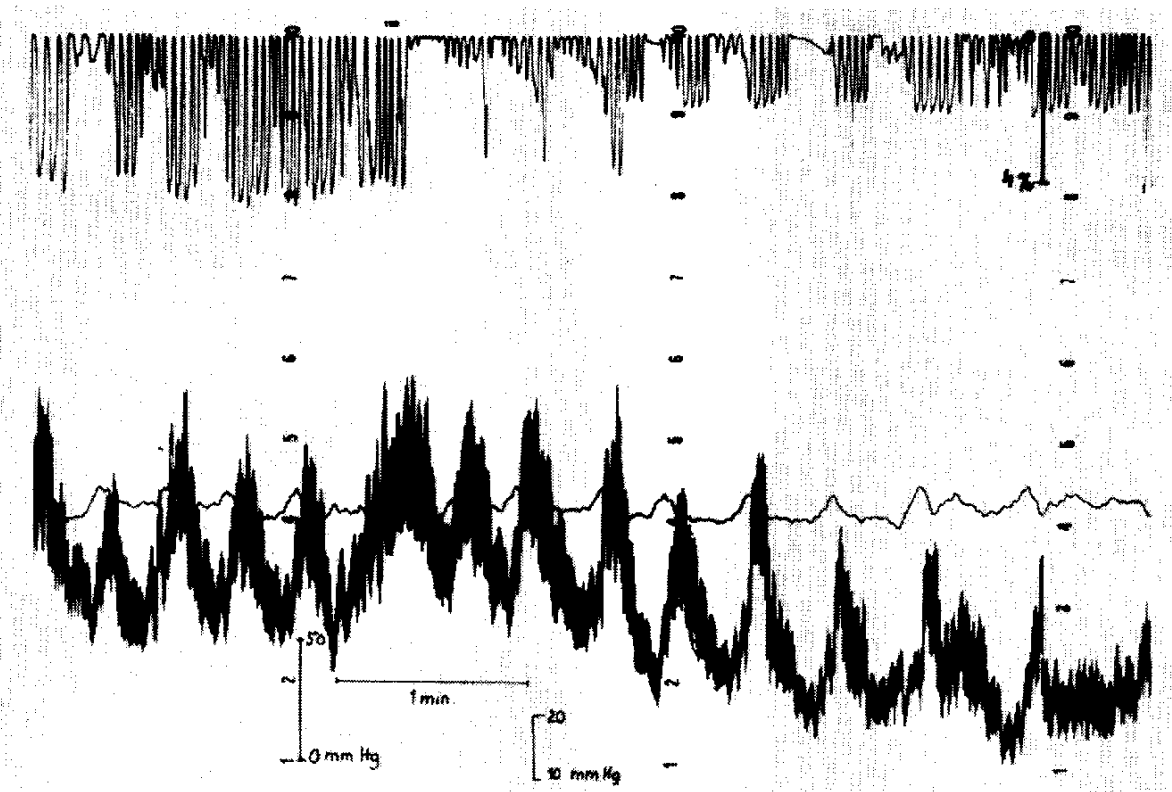

Fig. 6 VFP monitoring in a case of metastatic cancer in the vermis. The upper row is the same as in previous figures. The middle row shows integrated values of blood pressure. The lower row demonstrates the periodic $\mathrm{C}$ waves correlated precisely with periodically decreased breathing that changes the blood pressure periodically. The ICP reaches a certain point at a characteristic level and at that point normalized breathing occurs.

invasive, and they require puncture or drainage of CSF spaces or implantation of some kind of transducers or sensors. The limitations and disadvantages of such methods have led researchers to look for indirect ways of estimation of ICP dynamics.
One of the first of such attempts was the calculation of ICP level from the cerebral echo-pulsation on the basis of empirical data. ${ }^{24)}$ These pulsations are thought to be the result of changes in cerebral volume during the systolic period because these volume- 


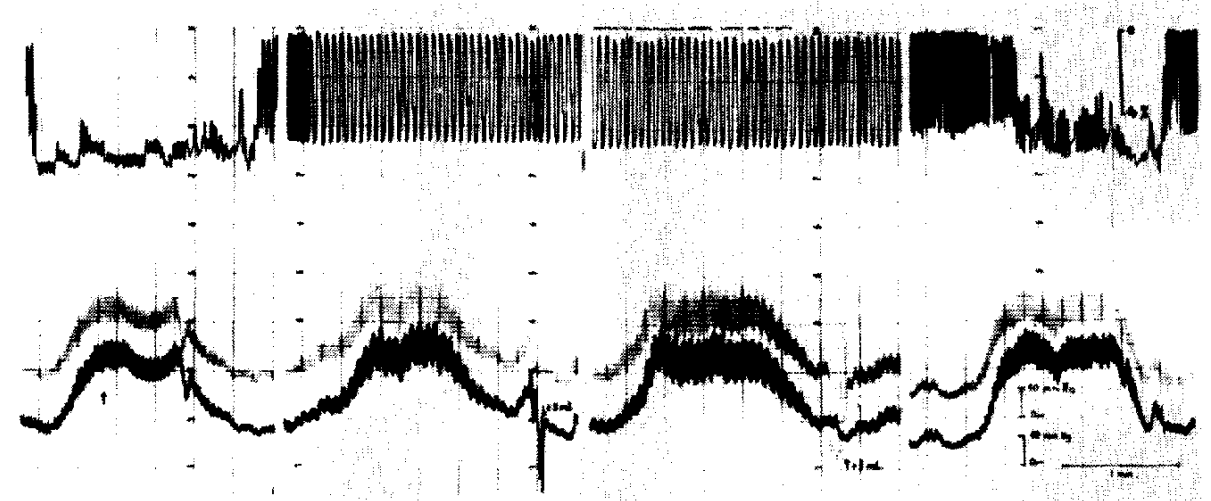

Fig. 7 CSF volume and CBV load test through the left and fourth ventricles successively in a case of operated spongioblastoma of the vermis complicated with late meningitis. The left ventricle has been shunted and the fourth ventricle was supposed to be occluded. Upper row as previously. The lower rows demonstrate the left and fourth ventricular pressures. Each kind of volume load caused pressure reactions in both CSF compartments similar to those caused by the pressing of the shunt (arrow). This proves that there was a good communication between the ventricles, and separate shunting of the fourth ventricle could thus be avoided.

changes alter the reflecting surfaces of the ultrasound. In patients with increased ICP there is a shortening of the rise time of the echo-pulsation and also a shortening of the delay between carotid and echo pulsations.

It has been demonstrated that CBV changes in each cardiac cycle show the volume/pressure relationship at that moment. With echo or diaphanic methods, changes in intracranial volume seem to be detectable. When ICP rises the pressure gradient across the walls of cerebral vessels decreases and the level of pulsation of the whole intracranial content increases. Thus, when amplitudes of cerebral pulsation and increasing $\mathrm{CBV}$ are recorded under precise control $\left(\mathrm{CO}_{2}\right.$ inhalation or PEEP), the change of amplitudes during the change of CBV will be correlated with the measure of intracranial elastance.

\section{Future trends}

We are aware that the understanding of ICP dynamics will develop further. Sophisticated noninvasive telemetric methods will be employed using mathematics and data analysis. Thus it will become possible to indicate continuously intracranial elastance and CSF dynamics, two of the most important factors in the status of the neurosurgical patient.

\section{References}

1) Apuzzo, M. L., Weiss, M. H., Peterson, V., Small, B., Kurze, T. and Heiden, J. S.: Effect of positive and expiratory pressure ventilation on ICP in man. J. Neurosurg 46: 227-232, 1977.

2) Avezaat, C. J. J., Eijndhoven, J. H. M. and Wyper, D. J.: Effects of hypercapnia and arterial hypotension and hypertension on CSF pressure and intracranial volume/ pressure relationships. $J$. Neurol Neurosurg Psychiatry 43: 222-234, 1980.

3) Benabid, A. L., DeRougemont, J. and Barge, M.: CSF dynamics: a mathematical approach. In Lundberg, N. (ed): ICP II. Springer, Berlin, 1975, pp 54-60.

4) Børgesen, S. E., Gjerris, F. and Sørensen, S. C.: CSF conductance and compliance of the craniospinal space in normal-pressure hydrocephalus. $J$ Neurosurg 51:521-525, 1979.

5) Cohadon, F., Castel, J. P., Vandendriessche, M. and Jeganed, D.: Effect of jugular compression on ICP. Neurochirurgia 19: 33-42, 1976.

6) Ekstedt, J.: CSF dynamic studies in man, 2: Normal hydrodynamic variables related to CSF pressure and flow. $J$ Neurol Neurosurg Psychiatry 41 : 345-353, 1978.

7) Goldensohn, E. S., Whitehead, R. W., Parry, T. M. and Spencer, J. N.: Studies on diffusion respiration, IX: $\mathrm{CO}_{2}$ on $\mathrm{CSF}$ 
pressure of anesthetized dogs. Am $J$ Physiol 165: 334-340, 1951.

8) Guillaume, J. and Janny, P.: Manométrie intracranienne continue. Rev Neurol 84: 131-142, 1951.

9) Hamer, J., Alberti, E., Hoyer, S. and Wiedemann, K.: Influence of systemic and cerebral vascular factors on the CSF pulse waves. $J$ Neurosurg 46: 36-45, 1977.

10) Katzman, R. and Hussey, F.: A simple constant infusion manometric test for measurement of CSF absorption. Neurology 20: 534-544, 1970.

11) Langfitt, T. W.: Increased intracranial pressure. Clin Neurosurg 16: 436-471, 1969.

12) Løfgren, J.: Effects of variations in arterial pressure and arterial $\mathrm{CO}_{2}$ tension on the CSF pressure/volume relationships. Acta Neurol Scand 49: 586-598, 1973.

13) Lundberg, N.: Continuous recording and control of ventricular fluid pressure in neurosurgical practice. Acta Psychiatr Scand [Suppl] 149, 1960.

14) Marmarou, A, Shulman, K, and LaMorgese, J.: Compartmental analysis of compliance and outflow resistance of the cerebrospinal system. I Neurosurg 43: 523-534, 1975.

15) Miller, J. D., Sullivan, H. G. and Becker, D. P.: CSF pressure/volume studies and hydrocephalus. I Neurosurg Sci 22: 147-158, 1978 .

16) Nornes, H., Aaslid, R. and Lindegaard, K. F.: Intracranial pulse pressure dynamics in patients with intracranial hypertension. Acta Neurochir 38: 177-186, 1978.

17) Nyáry, I., Vajda, J. and Pásztor, E.: Clinical experiences with intracranial volume/pressure response. In Shulman, K. (ed): ICP IV. Springer, Berlin, 1979, pp 116-119.
18) Paraicz, E. and Vajda, J.: Arterial and respiratory influences on ICP in infancy. Surg Neurol 4: 361-366, 1975.

19) Paraicz, E. and Vajda, J.: Fortläufende Registrierung der intraventrikularen Druckwellen bei Hydrocephalus im Säuglingsalter. Neurochirurgia 18: 43-52, 1975.

20) Pásztor, E. Pásztor, A., Bodó, M. and Bogsch, S.: The role of spinal subarachnoid space in compensation of intracranial hypertension. In Lundberg, N. (ed): ICP II. Springer, Berlin, 1975, pp 84-89.

21) Ryder, H. W., Espey, F. F., Kristoff, F. V. and Evans, J. P.: Observations on the interrelationships of ICP and CBF. $J$ Neurosurg $8: 46-58,1951$.

22) Shulman, K. and Marmarou, A.: Pressurevolume considerations in infantile hydrocephalus. Dev Med Child Neurol 13 [Suppl] $25 ; 90-95,1971$.

23) Sullivan, H. G., Miller, J. D, and Griffith, R. L.: Bolus versus steady state infusion for determination of CSF outflow resistance. Ann Neurol 5: 228-238, 1979.

24) terBraak, J. W. G. and deVlieger, M.: Cerebral pulsations in echo-encephalography. Acta Neurochir 12: 678-688, 1964.

25) Vajda, J., Nyáry, I. and Horváth, M.: Ventriculolymphatic shunt and decompensated intracranial volume/pressure relationship. Acta Neurochir [Suppl] 28: 521-525, 1979.

26) Vajda, J. and Paraicz, E.: The importance of ICP recording in clinical practice. Acta Univ Carol 75: 146-148, 1976.

27) Wilkinson, H. A., Schuman, N. and Ruggiero, J.: Nonvolumetric methods of detecting impaired intracranial compliance or reactivity. J Neurosurg 50: 758-767, 1979. 